\title{
BMJ Open What fluids are given during air ambulance treatment of patients with trauma in the UK, and what might this mean for the future? Results from the RESCUER observational cohort study
}

\author{
David N Naumann, ${ }^{1,2}$ James M Hancox,,${ }^{1,3,4}$ James Raitt, ${ }^{5}$ lain M Smith, ${ }^{1}$ \\ Nicholas Crombie, ${ }^{1}$ Heidi Doughty, ${ }^{6}$ Gavin D Perkins, ${ }^{7}$ Mark J Midwinter, ${ }^{2,8}$ The \\ RESCUER Collaborators
}

To cite: Naumann DN, Hancox JM, Raitt J, et al. What fluids are given during air ambulance treatment of patients with trauma in the UK, and what might this mean for the future? Results from the RESCUER observational cohort study. BMJ Open 2018;8:e019627. doi:10.1136/ bmjopen-2017-019627

- Prepublication history for this paper is available online. To view these files, please visit the journal online (http://dx.doi. org/10.1136/bmjopen-2017019627).

Received 14 September 2017 Revised 16 November 2017 Accepted 5 December 2017

Check for updates

For numbered affiliations see end of article.

Correspondence to Dr David N Naumann; david.naumann@nhs.net

\section{ABSTRACT}

Objectives We investigated how often intravenous fluids have been delivered during physician-led prehospital treatment of patients with hypotensive trauma in the UK and which fluids were given. These data were used to estimate the potential national requirement for prehospital blood products (PHBP) if evidence from ongoing trials were to report clinical superiority.

Setting The Regional Exploration of Standard Care during Evacuation Resuscitation (RESCUER) retrospective observational study was a collaboration between $11 \mathrm{UK}$ air ambulance services. Each was invited to provide up to 5 years of data and total number of taskings during the same period.

Participants Patients with hypotensive trauma (systolic blood pressure $<90 \mathrm{~mm} \mathrm{Hg}$ or absent radial pulse) attended by a doctor.

Primary and secondary outcome measures The primary outcome was the number of patients with hypotensive trauma given prehospital fluids. Secondary outcomes were types and volumes of fluids. These data were combined with published data to estimate potential national eligibility for PHBP.

Results Of 29037 taskings, 729 (2.5\%) were for patients with hypotensive trauma attended by a physician. Half were aged $21-50$ years; $73.4 \%$ were male. A total of 537 out of $729(73.7 \%)$ were given fluids. Five hundred and ten patients were given a single type of fluid; 27 received $>1$ type. The most common fluid was $0.9 \%$ saline, given to $486 / 537$ (90.5\%) of patients who received fluids, at a median volume of 750 (IQR 300-1500) mL. Three per cent of patients received PHBP. Estimated projections for patients eligible for PHBP at these 11 services and in the whole UK were 313 and 794 patients per year, respectively. Conclusions One in 40 air ambulance taskings were manned by physicians to retrievepatients with hypotensive trauma. The most common fluid delivered was $0.9 \%$ saline. If evidence justifies universal provision of PHBP, approximately 800 patients/year would be eligible in the UK, based on our data combined with others published. Prospective investigations are required to confirm or adjust these estimations.
Strengths and limitations of this study

- This study's main strength is that it reports data from the largest air ambulance collaboration to date and might be used by National Health Service leaders and blood transfusion services to estimate regional and national resource requirements.

- The study is limited by selection bias, since the majority of collaborating sites did not provide prehospital blood products; comparison is made with other published studies in order to place the current study data in context.

- Since only patients with hypotensive trauma were eligible for this study, no data are available regarding other patient groups that might require fluid resuscitation, such as those with gastrointestinal or obstetric haemorrhage.

- The study is further limited by unavailability of haematological data (such as haemoglobin level) within the prehospital environment, as well as limited data regarding specific injury details or severity scores.

- Patient outcomes were not examined within the limitations of this retrospective observational study, and future prospective investigations should aim to examine these in relation to specific interventions.

\section{INTRODUCTION}

Hypovolaemic shock following trauma may lead to reduced perfusion of vital organs, with resultant oxygen debt, tissue hypoxia and acidosis. Intravenous resuscitation fluids are commonly given in this clinical scenario by prehospital teams during emergency evacuation to hospital, as recommended by the UK Ambulance Services Clinical Practice Guidelines and the National Institute for Health and Care Excellence (NICE). ${ }^{12}$ The principle aim of such an intervention is to restore circulatory volume and cardiac output 
and improve perfusion of vital organs through increased microcirculatory flow. The most suitable fluid for prehospital resuscitation is controversial; there is no widespread consensus in the UK on which should be given to patients in this context, with a recent large prospective observational study ${ }^{3}$ and a meta-analysis of observational studies ${ }^{4}$ not offering a definitive answer. Some prehospital services within the UK now provide blood products in the prehospital environment, ${ }^{56}$ whereas others do not. There is some uncertainty regarding how many patients in the UK would require prehospital blood products (PHBP) if National Health Service (NHS) leaders were to instigate universal national provision, since no nationwide assessment of fluid delivery in patients with trauma has been conducted.

The UK air ambulances are autonomous charitable organisations that operate alongside NHS ground ambulance services as components of major trauma networks. In addition to transporting injured patients to trauma units or regional major trauma centres (as appropriate), air ambulances may deliver specialist prehospital emergency medical (PHEM) doctors and critical care paramedics to incident scenes in order to provide on-scene and en route resuscitation. These prehospital practitioners are able to deliver fluids in the prehospital treatment and evacuation of patients, but exactly what fluids have been delivered has not previously been examined in detail. There are three randomised controlled trials (RCTs) currently examining PHBP versus standard care following trauma: from the USA, UK and France. ${ }^{7-9}$ In the UK, the Resuscitation with PreHospItaL bLood Products (RePHILL) trial is investigating whether packed red blood cells and freeze-dried plasma are superior to $0.9 \%$ saline (designated as 'standard care') during prehospital evacuation of patients with trauma. ${ }^{8}$ In order to place this trial into context of 'standard care', a study of current prehospital fluid resuscitation practice for patients with trauma in the UK is warranted.

The aims of the current study were to determine how often resuscitation fluids are delivered in the UK for the prehospital treatment of patients with hypotensive trauma, what types of fluids are most commonly delivered and how these data might affect national resource planning for the universal prevision of PHBP if the results of ongoing RCTs $^{7-9}$ show clinical efficacy.

\section{METHODS}

\section{Study design and setting}

All air ambulance services in the UK were invited to collaborate in a research project to investigate the delivery of prehospital fluids for patients with trauma, designated as the Regional Examination of Standard Care dUring Evacuation Resuscitation (RESCUER) study, which employed a retrospective observational design. As a service evaluation using routine data, Research Ethics Committee approval was not required for this study (as confirmed by the online NHS Health Research Authority decision-making tool (http://www.hra-decisiontools.org. $\mathrm{uk} / \mathrm{research} /)$ ). Each contributing centre ensured that they had appropriate institutional approval for the use of all data. All air ambulance services undertake their own internal performance and quality reviews.

\section{National air ambulance research collaboration}

All 22 air ambulance organisations in the UK were invited to collaborate in January 2016. First contact was made using a standardised, carbon copied email to representatives at each service, and then followed up at regular intervals by email and telephone until every centre declared that they wished to collaborate or declined. Coordination, communication and administration of the collaboration was undertaken at a single research centre in the West Midlands. Each centre was sent a study protocol and blank data sheet for completion. The time window for centres to respond to the request to provide data was a period of 12 months (January 2016-December 2016). Identical blank datasheets were sent to centres in order to reduce the risk of bias or heterogeneity between centres.

\section{Patient selection criteria}

Prior to the start of the study, it was considered likely that there would be heterogeneity among air ambulance services with regards to their site-specific protocols for fluid resuscitation eligibility. Inclusion criteria for this study were therefore chosen a priori to be identical to those of an ethically approved UK-based RCT (the RePHILL study) that investigates fluid delivery within the prehospital environment. ${ }^{8}$ Within these eligibility criteria, patients were included if they had sustained a traumatic injury, were attended by a PHEM team (which included a physician) and had a systolic blood pressure $<90 \mathrm{~mm} \mathrm{Hg}$ or absent radial pulse during their treatment and evacuation to hospital. The assumption was made that prehospital personnel would use the contralateral radial pulse in the presence of an upper limb injury. The decision to only include prehospital services with PHEMtrained physicians was made on the basis that this was the setting most likely to be amenable to prehospital transfusion of blood products during the study period. Patients were excluded if they died before being given any fluids. Interhospital transfers were also excluded.

\section{Data collection and management}

Patients were identified at each air ambulance centre from contemporaneous prehospital documentation held by the ambulance services. Collaborators were asked to provide up to 5 years of retrospective data, but shorter periods were accepted, since it was anticipated that data storage and retrieval would vary between services. All centres were also asked to provide the total number of prehospital taskings during the same period in order to provide a contextual denominator. Details regarding patient characteristics included age and gender, mechanism of injury and physiological parameters (such as blood pressure and heart rate). Details regarding medical 
evacuation included timings and delivery of prehospital tranexamic acid. The resuscitation fluid types and volumes were recorded for the entire prehospital period. Only prehospital records were examined by air ambulance services, and inhospital records were not available for included patients.

Anonymised data were sent via password-encrypted NHS email to the central coordinator of the collaboration, and all data were combined. All data were screened by two authors (DNN and JMH) to ensure that eligibility criteria were correctly applied and consistent between centres. These data were kept on a password-encrypted NHS computer within a restricted-entry research facility. The primary outcomes of interest were the type and volume of intravenous fluids delivered to patients during their prehospital treatment and evacuation to hospital. No power calculation was undertaken, since there were no comparisons planned at the outset of the study.

For the purposes of potential future resource planning, an estimation was made for the projected number of patients per year that would be eligible for PHBP provision, on the assumption that the eligibility criteria would be the same as those in the current study. This was performed by dividing the total number of eligible patients at each site by the number of months of data provided by that site, and then multiplying by 12 . These figures were added together in order to derive an approximate number of patients per year for the whole cohort of 11 sites. In order to provide an estimation for the total projected annual resource requirement for the UK, these data were combined with the data from four published studies, ${ }^{510-12}$ and then projected for all 22 UK sites on the assumption that these combined sites were a representative sample of the whole. This assumption was considered to be acceptable, since the included sites consisted of an adequate mix of urban and rural sites across the UK.

\section{RESULTS}

\section{National air ambulance collaboration}

Of a possible 22 air ambulance services, 11 provided data for the collaboration. Four of the sites were willing to collaborate but could not be included because they did not have prehospital physicians on board, and a further seven were unable to collaborate. Some reasons for non-collaborations were non-availability of personnel or time for research activity, desire not to duplicate data from other studies and inadequate facilities to enable retrospective review of medical records of fluid data. All 22 sites provided basic data regarding aircraft, geographical locations, whether they carried doctors and whether they provided PHBPs (table 1).

\section{Data collection tools}

Of the 11 centres, all currently use dedicated electronic databases for data collection from air ambulance missions. One centre had also used paper records for part of their data collection. Two centres used only EasyTask
(EuroAvionics, Slinfold, UK), two used only HEMSBase (Medic One Systems, Tadworth, UK), and one centre transferred from the former to the latter during the study period. Three centres used Access (Microsoft, Redmond, USA) and one used Filemaker (Apple, Cupertino, USA). The remainder did not specify the electronic database that was used.

\section{Patient characteristics}

There were 29037 taskings during the relevant study period, and patient-level data was provided for 729 $(2.5 \%)$ patients who fulfilled all study inclusion criteria. Figure 1 illustrates the number of patients and the date ranges provided by all centres. Their demographic and injury details are shown in table 2.

\section{Timing of evacuation}

The time interval between the emergency call and arrival of the medical team was available for 597 patients; the median was 25 (IQR 19-35) min. The combined on-scene and transfer time (interval between arrival of medical team and arrival of patient in hospital) was available for 566 patients, and the median was 53 (IQR 39-73) min.

\section{Resuscitation during evacuation}

The initial physiological parameters that were obtained during treatment for all patients during the prehospital period (combined on-scene and transfer) are summarised in table 3. During prehospital treatment of the patients, $342(46.9 \%)$ patients received TXA. One hundred and ninety two (26.3\%) patients received no fluids. Of the $537(73.7 \%)$ patients who received at least one type of fluid, $510(95.0 \%)$ received a single type of fluid, and $27(5.0 \%)$ received more than one type. The types of fluid delivered to patients during their prehospital treatment and transfer to hospital are summarised in table 4. Five hundred and twenty-one $(97.0 \%)$ received crystalloid fluids only, $11(2 \%)$ received blood products only and $5(1 \%)$ received both crystalloids and blood products.

Of all patients who received prehospital fluids, $0.9 \%$ saline was given to $486 / 537$ (90.5\%), with a median volume administered of 750 (IQR 300-1500) mL. Figure 2 illustrates the frequency distribution of volume of $0.9 \%$ saline delivered to study patients during their prehospital treatment and transfer and ranged from $40 \mathrm{~mL}$ to $4000 \mathrm{~mL}$. Hartmann's solution was delivered to $33 / 537$ (6.1\%) patients with a median volume of 750 (IQR 500-1375) mL. Twenty-four out of 537 (4.5\%) patients were given hypertonic saline, with a median volume of 350 (IQR 162-350) mL.

\section{National resource management projection}

When the projected number of patients fulfilling eligibility criteria were examined for each study site, there was a wide range of eligible patients, ranging from 4 to 83 patients per year (figure 1). The combined total number of patients that fulfilled eligibility criteria for all 11 air ambulance services was 297 per year. In addition, 
Table 1 Summary of service provision by UK air ambulance charities

\begin{tabular}{|c|c|c|c|c|}
\hline Air ambulance & Aircraft & Air base & $\begin{array}{l}\text { Carries } \\
\text { doctor? }\end{array}$ & $\begin{array}{l}\text { Carries blood } \\
\text { products? }\end{array}$ \\
\hline Cornwall Air Ambulance Trust ${ }^{\star}$ & HMED01 & Newquay & Not & No \\
\hline Derbyshire, Leicester and Rutland Air Ambulanceł & HMED54 & East Midlands Airport & Yes & No \\
\hline \multirow[t]{2}{*}{ Devon Air Ambulance } & HMED70 & Exeter & Yes & No \\
\hline & HMED71 & Eaglescott & No & No \\
\hline Dorset and Somerset Air Ambulanceł & HMED10 & Henstridge & Yes & Yes \\
\hline \multirow[t]{2}{*}{ East Anglian Air Ambulance $\neq$} & HMED85 & Norwich & Yes & No \\
\hline & HMED88 & Cambridge & Yes & No \\
\hline \multirow[t]{2}{*}{ Essex and Herts Air Ambulanceł } & HMED07 & Earls Colne & Yes & No \\
\hline & HMED55 & North Weald & Yes & No \\
\hline \multirow[t]{2}{*}{ Great North Air Ambulance } & HMED58 & Langwathby & Yes & Yes \\
\hline & HMED63 & Durham Tees Valley & Yes & Yes \\
\hline Great Western Air Ambulance Charity $\ddagger$ & HMED65 & Filton & Yes & Yes \\
\hline Hampshire and Isle of Wight Air Ambulance & HMED56 & Thruxton & Yes & Yes \\
\hline \multirow[t]{2}{*}{ Kent Surrey Sussex Air Ambulance } & HMED21 & Marden & Yes & Yes \\
\hline & HMED 60 & Redhill & Yes & Yes \\
\hline Lincolnshire and Nottinghamshire Air Ambulanceł & HMED29 & RAF Waddington & Yes§ & No \\
\hline \multirow[t]{2}{*}{ London's Air Ambulance } & HMED27 & Royal London/Northolt & Yes & Yes \\
\hline & HMED28 & Royal London/Northolt & Yes & Yes \\
\hline Magpas $\ddagger$ & HMED66 & RAF Wyton & Yes & No \\
\hline \multirow[t]{3}{*}{ Midlands Air Ambulanceł } & HMED03 & Cosford & Yes & No \\
\hline & HMED06 & Strensham & No & No \\
\hline & HMED09 & Tatenhill & No & No \\
\hline \multirow[t]{3}{*}{ North West Air Ambulance* } & HMED08 & Blackpool Airport & Not & No \\
\hline & HMED72 & Barton Airfield & No† & No \\
\hline & HMED75 & Barton Airfield & Not & No \\
\hline \multirow[t]{2}{*}{ Scottish Ambulance Serviceł } & HMED02 & Inverness & No & No \\
\hline & HMED05 & Glasgow & Yes & Yes \\
\hline Scotland's Charity Air Ambulance* & HMED76 & Perth Airport & No & No \\
\hline Thames Valley Air Ambulance & HMED24 & RAF Benson & Yes & Yes \\
\hline \multirow[t]{3}{*}{ Wales Air Ambulance Charitable Trust } & HMED57 & Swansea & Yes & Yes \\
\hline & HMED59 & Welshpool & Yes & Yes \\
\hline & HMED61 & Caernarfon & No & No \\
\hline $\begin{array}{l}\text { Warwickshire and Northamptonshire Air } \\
\text { Ambulance } \neq\end{array}$ & HMED53 & Coventry Airport & Yes & No \\
\hline Wiltshire Air Ambulance* & HMED22 & Devizes & No & Yes \\
\hline \multirow[t]{2}{*}{ Yorkshire Air Ambulanceł } & HMED98 & Nostell & Yes & No \\
\hline & HMED99 & Topcliffe & No & No \\
\hline
\end{tabular}

*Ineligible for current study.

†Did not carry doctors during the majority of study period.

‡Collaborators.

§Ad hoc basis only for some of study period.

published data on one collaborating site (Great Western Ambulance Service (68/year) $)^{12}$ were combined with the data from the current study, giving a total of 313 patients per year for the 11 collaborating services. This figure represents the estimated number of patients per year that would require provision of blood products for $11 / 22$ UK air ambulance services if clinical evidence from RCTs were to justify their universal provision.

In order to estimate the number of potentially eligible patients in the whole UK, further data from three 


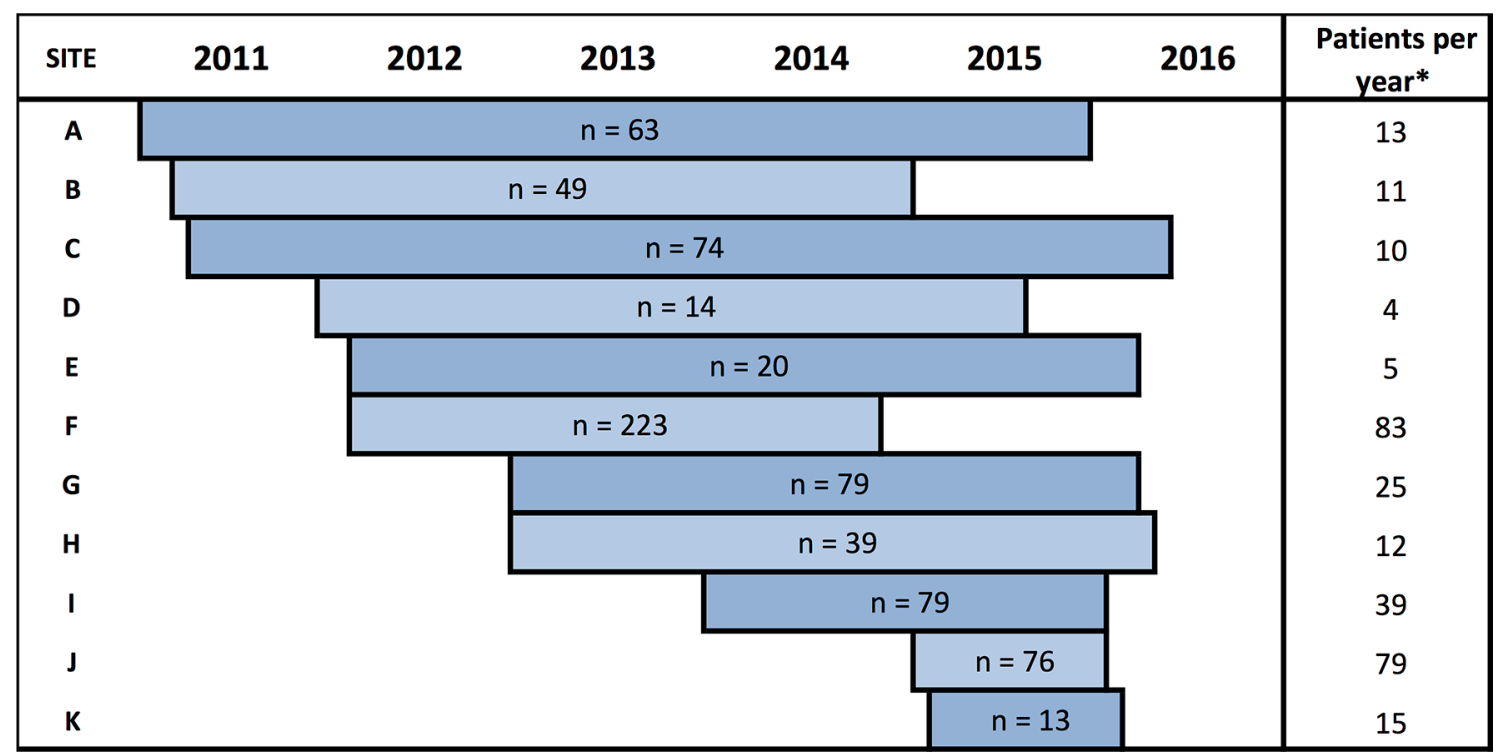

Figure 1 Date ranges and number of included patients according to anonymised collaborating site. *Number of patients per year are derived by the number of patients divided by the number of months of data provided, multiplied by 12 .

non-collaborating sites (Thames Valley Air Ambulance (30/year),${ }^{10}$ Kent Surrey \& Sussex Air Ambulance (80/ year), ${ }^{5}$ and London's Air Ambulance $(82 /$ year $\left.)\right)^{11}$ were added to the current study data, giving a combined total of 505 patients per year from 14 services. Based on the assumption that the sample was representative of the population, the estimated projection for all 22 sites in the UK was 794 patients per year.

\section{DISCUSSION}

The current study has found that one in every 40 air ambulance taskings during the study period was for a patient with hypotensive trauma that was attended by a physician and that three quarters of these patients were given intravenous fluids. The most common type of fluid delivered in this context was $0.9 \%$ saline, which was administered to more than $90 \%$ of those patients who received any fluid. Our findings confirm that the most common prehospital fluid for patients with hypotensive trauma in the UK is $0.9 \%$ saline, at an average of $750 \mathrm{~mL}$. If ongoing RCTs $^{7-9}$ provide enough evidence for universal national provision of PHBP throughout the UK, the data from the current study estimate that just over 300 patients per year would fulfil eligibility criteria for these 11 air ambulance services and just under 800 patients per year for the whole UK. The current study used a relatively straightforward study design to establish a national air ambulance research collaboration in the UK and was able to examine data from 729 patients evacuated by 11 air ambulance services that supported a range of urban and rural areas. To our knowledge, the largest previous air ambulance collaboration involved nine air ambulance services in the USA. ${ }^{13}$

The majority of air ambulance services who collaborated in this study were those that do not provide PHBPs. UK NICE guidelines support the delivery of crystalloid fluid in the absence of blood products, ${ }^{2}$ and recent European guidelines recommend isotonic crystalloid fluid be delivered to patients with hypotensive trauma. ${ }^{14}$ However, it is acknowledged that there are 14 helicopters in 10 services that currently provide blood products during prehospital evacuation in the UK (table 1). The retrospective and sampling nature of the study meant that either non-participation or newly instigated provision of blood products may not have been captured within the data sets and that the current study findings are subject to selection bias. Nevertheless, our study was able to illustrate the regional heterogeneity among services and provide an estimated projection that might be used by NHS leaders for service provision, if results from RCTs show clinical superiority of PHBP. Four of the air ambulance services that carry blood on board have published data on their use of PHBPs (table 5)..$^{510-12}$ The demographics of these patients are similar to that found in our study (table 2), with predominantly adult males under the age of 50 years and blunt trauma. The data from London's Air Ambulance shows the unique case mix of this urban, trauma only service with a relatively higher proportion of penetrating trauma. Most patients in these case series were transfused an average of 2 units (approximately $600 \mathrm{~mL}$ of packed red blood cells). The number of patients transfused per year from these four cohort studies ranges from 30 to 82 patients per year, which is in keeping with the range of eligible patients from the RESCUER study data (figure 1). The current study sample is likely to represent the patients who would be eligible for PHBP if it were considered to be the optimal evidence-based management strategy, since the eligibility criteria were identical to those that have been approved by a Research Ethics Committee for an ongoing RCT of PHBPs versus crystalloid fluids for trauma. ${ }^{8}$

Two RCTs have investigated the efficacy of crystalloid delivery to patients with trauma within the prehospital 


\begin{tabular}{|c|c|c|}
\hline Characteristic & 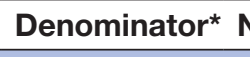 & N (\%) \\
\hline Male gender & 683 & $501(73.4)$ \\
\hline Age category & 716 & \\
\hline $0-10$ & & $34(4.7)$ \\
\hline $11-20$ & & $69(9.6)$ \\
\hline $21-30$ & & $141(19.7)$ \\
\hline $31-40$ & & $90(12.6)$ \\
\hline $41-50$ & & $106(14.8)$ \\
\hline $51-60$ & & $111(15.5)$ \\
\hline $61-70$ & & $69(9.6)$ \\
\hline $71-80$ & & $54(7.5)$ \\
\hline$>80$ & & $42(5.9)$ \\
\hline Mechanism of injury & 695 & \\
\hline \multicolumn{3}{|l|}{ Road traffic accident } \\
\hline In vehicle & & $207(29.8)$ \\
\hline Pedestrian & & $104(15.0)$ \\
\hline Motorcyclist & & 90 (12.9) \\
\hline Cyclist & & $35(5.0)$ \\
\hline Unspecified & & $17(2.4)$ \\
\hline Fall & & $92(13.2)$ \\
\hline Assault & & $62(8.9)$ \\
\hline Self-harm & & $39(5.6)$ \\
\hline Leisure and sports & & $14(2.0)$ \\
\hline Industrial & & $8(1.2)$ \\
\hline Crush & & $8(1.2)$ \\
\hline Railway & & $7(1.0)$ \\
\hline Agricultural & & $4(0.6)$ \\
\hline Impalement & & $3(0.4)$ \\
\hline Limb amputation & & $2(0.3)$ \\
\hline Gun shot wound & & $2(0.30)$ \\
\hline Dog bites & & $1(0.1)$ \\
\hline Blunt or penetrating injury & 707 & \\
\hline Blunt & & 654 (92.5) \\
\hline Penetrating & & $53(7.5)$ \\
\hline
\end{tabular}

*indicates number with available data. Summary data are expressed using this number as a denominator.

environment when compared with delayed delivery (inhospital). ${ }^{1516}$ The first of these reported that prehospital crystalloid delivery was associated with higher mortality and number of complications among patients
Table 4 Type of intravenous fluid delivered to patients during their prehospital treatment and transfer to hospital

\begin{tabular}{lc}
\hline Fluids & N (\%) \\
\hline Total & $729(100)$ \\
\hline Single type of fluid & \\
$\quad$ 0.9\% saline & $464(63.6)$ \\
\hline Hartmann's & $31(4.3)$ \\
\hline PRBCs & $10(1.4)$ \\
\hline Hypertonic saline & $4(0.5)$ \\
\hline 10\% dextrose & $1(0.1)$ \\
Multiple types of fluid & \\
\hline 0.9\% saline and hypertonic saline & $20(2.7)$ \\
\hline 0.9\% saline and PRBCs & $4(0.5)$ \\
\hline 0.9\% saline and Hartmann's & $1(0.1)$ \\
\hline Hartmann's and PRBCs & $1(0.1)$ \\
\hline PRBCs and FFP & $1(0.1)$ \\
No fluids & $192(26.3)$ \\
\hline
\end{tabular}

FFP, fresh frozen plasma; PRBC, packed red blood cells.

with penetrating torso injury when compared with delayed delivery. ${ }^{16}$ The second reported no significant difference in mortality between early or delayed crystalloid infusion, but protocol compliance was poor. ${ }^{15}$ Further observational studies also have conflicting results regarding prehospital crystalloid delivery, reporting equivalent, ${ }^{17}{ }^{18}$ superior ${ }^{19}$ or poorer ${ }^{20}$ outcomes when compared with no fluid delivery. The current study reports a wide range of volumes of crystalloid delivered to patients with traumaincluding no fluid at all-which would be based on the clinical parameters during the prehospital period and physician judgement. It is likely that a tailored approach is required for prehospital resuscitation, ${ }^{21}$ and specific patient groups should be investigated separately in order to determine which may benefit from prehospital crystalloid resuscitation fluid. Our study demonstrates that large-scale collaboration of prehospital services in the UK is feasible and provides a framework for such bespoke investigations to be undertaken. A UK national research collaborative is warranted in order to design and implement studies regarding outcomes following prehospital fluid resuscitation.

Organisations such as the WHO and the Institute of Medicine of the National Academies have reported that there is a relative lack of evidence in prehospital practice when compared with other medical specialties. ${ }^{2223}$ Several factors hinder prehospital research, most obviously the

Table 3 Initial physiological parameters for patients during prehospital treatment and evacuation

\begin{tabular}{llll}
\hline Parameter & First recorded & Second recorded & Third recorded \\
\hline Systolic blood pressure* $^{*}$ & $82(60-95)$ & $85(68-104)$ & $91(70-112)$ \\
Heart rate* $^{*}$ & $98(77-120)$ & $97(76-120)$ & $98(80-119)$ \\
\hline
\end{tabular}

${ }^{*}$ All values are given as median and IQR in parentheses. 


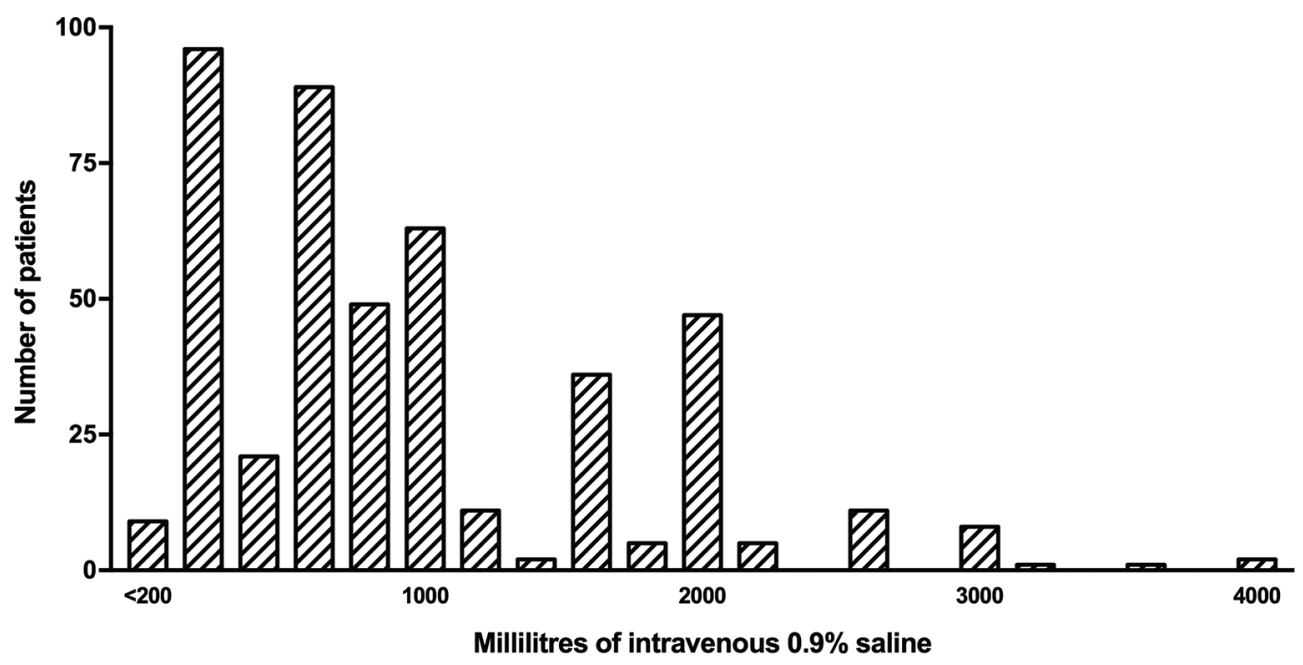

Figure 2 Volumes of $0.9 \%$ saline delivered to study patients.

need for a small prehospital team to prioritise clinical care over the research process. Other factors may include limited data storage and access, and logistic, manning and financial constraints. Treating research as a normal rather than extraordinary part of prehospital practice may improve study participation. ${ }^{24}$ Recent UK collaborations have used research networks ${ }^{25-27}$ and student-led associations $^{28}$ to answer questions related to clinical practice, but to our knowledge, there has been no previous large-scale UK air ambulance research collaboration.

\section{Limitations and future research}

The prehospital air ambulance services in the UK are heterogenous, and each is run independently. We used the overall number of tasking as a contextual denominator but recognise that this is only an approximate measure, since some services are tasked only to trauma, others attend trauma and medical emergencies and others attend lower acuity 'admission avoidance' cases as well as medical and trauma emergencies. This study found that each air ambulance uses its own data collection tool and had different quantities accessible for retrospective analysis. There were wide variations in data provided by each site in both date ranges available and number of patients (as seen in figure 1). These variations between sites may be due to a combination of differences in search strategies used within the electronic records and genuine differences in workload between centres. Such a limitation is likely to be compounded by retrospective methodology, and future studies may reduce bias by using prospective data collection. Furthermore, heterogeneity may be reduced if sites agree to standardise data collection, storage and access. Although this might appear straightforward, the reality is more complex due to the independent and autonomous nature of air

Table 5 Published data regarding prehospital blood transfusion by UK air ambulances

\begin{tabular}{|c|c|c|c|c|}
\hline & $\begin{array}{l}\text { Thames Valley Air } \\
\text { Ambulance }\end{array}$ & $\begin{array}{l}\text { Kent Surrey Sussex Air } \\
\text { Ambulance }\end{array}$ & $\begin{array}{l}\text { London's Air } \\
\text { Ambulance }\end{array}$ & $\begin{array}{l}\text { Great Western Air } \\
\text { Ambulance }\end{array}$ \\
\hline Reference & Raitt et al ${ }^{10}$ & Lyon et $a l^{5}$ & Rehn et $a l^{11}$ & Hooper et al ${ }^{12}$ \\
\hline Publication type & Full text & Full text & Abstract & Abstract \\
\hline Date range & January 14-February 16 & $\begin{array}{l}\text { February 13-December } \\
14\end{array}$ & $\begin{array}{l}\text { January 12-December } \\
15\end{array}$ & August $15-J u l y ~ 16$ \\
\hline N/year* & 30 & 80 & 82 & 68 \\
\hline Age, median (range) & $40(13-89)$ & $42(9-92)$ & 31 & Not reported \\
\hline Male, \% & 74.6 & 78 & 79 & Not reported \\
\hline Blunt injury, \% & 84 & 90 & 61 & Not reported \\
\hline
\end{tabular}

${ }^{*}$ The same technique is used to calculate patients per year as described in figure 1.

ISS, injury severity score; PRBC, packed red blood cells; RESCUER, Regional Examination of Standard Care during Evacuation Resuscitation. 
ambulance charities. Future collaborations may be optimised by adopting a centralised structure, with consensus established between centres a priori about how to realise a true national research collaborative.

Some patients included in this study received intravenous hypertonic saline as a type of intravenous fluid within the prehospital environment. Most services have well-defined criteria for its use relating to raised intracranial pressure and brain herniation in patients with head injury, and it is not used for volume resuscitation of the patient with hypovolaemia.

The amount of data available for each patient within the resource-limited prehospital setting was relatively low when compared with studies within the inhospital environment. The current study is therefore limited by lack of desirable parameters such as haemoglobin or arterial blood gas parameters within the prehospital period. Furthermore, no inhospital parameters were available in the current study, since data were collected exclusively from prehospital records. Detailed descriptions of injuries were not available within the framework of prehospital data collection, and injury severity scores were not available for patients. Glasgow Coma Scales were not available, and it was unknown how many patients may have had an isolated brain injury. It is acknowledged that blood pressure and pulse are not the most ideal parameters for the decision to transfuse. There may be more sensitive and specific criteria, such as shock index or injury severity, as demonstrated in a recent large trauma registry study. ${ }^{29}$ However, a pragmatic approach was used in order to determine patient eligibility, reflecting the practice currently used within UK prehospital services.

Within the framework of a retrospective observational study, it was not possible to examine the decision-making process for each patient who was eligible for fluid resuscitation. Some eligible patients did not receive fluids, and it is likely that some patients that did not fit our inclusion criteria were given fluid resuscitation. Such uncertainty could be better addressed by prospective investigations that sought to examine real-time decision processes. Although each individual air ambulance service conducts their own internal performance and quality reviews, specific details from these were beyond the scope of the current study and were not included.

As each air ambulance service strives for improvements and optimal clinical outcomes, changes and developments in service provision are commonplace. This study presents the current state of the services at the time of writing, but these are subject to change as practice evolves. Our estimated projections of PHBP resource requirements are likely to be limited by being derived from retrospective data and the assumption that service requirements will not change. Any increase or decrease in service demand will lead to underestimation or overestimation, respectively. Furthermore, these data only represent those patients who may require fluids following trauma and did not include patients who require fluids for other indications such as obstetric or gastrointestinal haemorrhage. It is also acknowledged that data from the current study may not necessary be applicable to selected patients, such as those more severely injured, with severe shock, with longer transport times or in the military context of remote damage control resuscitation.

The current study did not examine clinical outcomes following fluid resuscitation. Physician-led prehospital care often involves multiple simultaneous interventions, and the retrospective observational design would not provide sufficiently robust data to allow attribution of effect to interventions. Future collaborative research should focus on funded, ethically approved protocols that aim to investigate interventions and their outcomes. Such work might benefit from centralised coordination by a recognised air ambulance entity such as the Air Ambulance Association.

\section{CONCLUSION}

Among 11 participating UK air ambulance services that carry physicians, there were 29037 total taskings, of which $2.5 \%$ retrieved patients with hypotensive trauma. Of these, three-quarters were given intravenous fluids. The most common fluid type in this context was $0.9 \%$ saline, with a median volume of $750 \mathrm{~mL}$. There is heterogeneity among UK services, with just under half currently providing prehospital either blood products or crystalloid fluids, and the remainder providing crystalloid fluids only. If RCTs report clinical superiority of PHBPs for patients with trauma, and universal provision is planned by NHS leaders, we estimate that just over 300 patients per year would require these within the 11 air ambulance services sampled and just under 800 patients per year in the whole UK. These estimations require prospective investigations to confirm or adjust.

\section{Author affiliations}

${ }^{1}$ NIHR Surgical Reconstruction and Microbiology Research Centre, Queen Elizabeth Hospital, Birmingham, UK

${ }^{2}$ College of Medical and Dental Sciences, University of Birmingham, Birmingham, UK

${ }^{3}$ West Midlands Ambulance Service NHS Foundation Trust, Brierley Hill, UK

${ }^{4}$ Midlands Air Ambulance Charity, Stourbridge, West Midlands, UK

${ }^{5}$ Thames Valley Air Ambulance, RAF Benson, Oxfordshire, UK

${ }^{6} \mathrm{NHS}$ Blood and Transplant, Birmingham, UK

${ }^{7}$ Critical Care Medicine, University of Warwick, Coventry, UK

${ }^{8}$ School of Biomedical Sciences, Faculty of Medicine, University of Queensland, Brisbane, Australia

Acknowledgements The authors wish to thank the following contributors who provided information for table 1 of the manuscript: David Rawlinson (Wales Air Ambulance Charitable Trust); Nigel Rees (Welsh Ambulance Service NHS Trust); Matthew Baskerville (Wiltshire Air Ambulance); Simon Brown (Thames Valley Air Ambulance); John Pritchard (Scotland's Charity Air Ambulance); Rachel Hawes (Great North Air Ambulance Service); David Sutton and Charles Deakin (Hampshire and Isle of Wight Air Ambulance); Clare Bosanko (Devon Air Ambulance Trust); Steve Garvey, Stuart Croft (Cornwall Air Ambulance Trust); and Richard Lyon, Malcolm Russell and Emily McWhirter (Kent, Surrey \& Sussex Air AmbulanceTrust). The authors also wish to acknowledge the NIHR Surgical Reconstruction and Microbiology Research Centre for their administrative assistance during this study.

Collaborators Daniel Evans, Jenny Conway and Caroline Leech (The Air Ambulance Service, Clifton House, Butlers Leap, Rugby, Warwickshire, UK); Simon 
Lewis and Natalie Church (Magpas Air Ambulance, Centenary House, St. Mary's Street, Huntingdon, Cambridgeshire, UK); Christopher von Mickwitz, Andrew Pountney, Fiona Bell and Jane Shewan (Yorkshire Ambulance Service NHS Trust, Springhill 2, Brindley Way, Wakefield 41 Business Park, Wakefield, UK); Phil Hyde, Michael Eddie and Michelle Walker (Dorset \& Somerset Air Ambulance, Landacre House, Castle Road, Chelston Business Park, Wellington, UK); Richard Hindson and Alastair Wilson (East Anglian Air Ambulance, Hangar E, Gambling Close, Norwich Airport, Norwich, UK); Stuart Elms and Christina Hood (Essex and Herts Air Ambulance, Flight House, Earls Colne Business Centre, Earls Colne Business Park, Earls Colne, Colchester, UK); Jules Blackham, Scott Grier and Vicki Brown (Great Western Air Ambulance Charity, County Gates, 3rd Floor, Ashton Road, Bristol, UK); Richard Irwin and Neil Clarke (Lincolnshire \& Nottinghamshire Air Ambulance, Bentley Drive, Bracebridge Heath, Lincoln, UK); Alasdair Corfield and Anne Cadman (EMRS Scotland, ScotSTAR, Hangar B, 180 Abbotsinch Road, Paisley, UK).

Contributors DNN, IMS, NC and MJM conceived, designed and developed the study protocol. DNN and JMH facilitated the multicentre collaboration. DNN, JMH, $\mathrm{NC}$ and all RESCUER collaborators performed data collection. DNN and JMH combined and cleaned data from all sites in the study. DNN, JMH, JR, IMS, HD and GP analysed and interpreted the data. The manuscript was written by DNN and was critically appraised by JMH, JR, IMS, NC, GP, HD and MJM. Further appraisal and revisions were made by all RESCUER collaborators for the final version of the manuscript.

Funding Open access fees are provided by the University of Birmingham.

Competing interests DNN, JMH, IMS, NC, GP, HD and MJM are investigators in the RePHILL (Resuscitation with PreHospltaL bLood Products) study, a multicentre randomised controlled trial of prehospital blood product administration versus standard care for traumatic haemorrhage.

Patient consent Not required.

Ethics approval As a service evaluation using routine data, Research Ethics Committee approval was not required for this study (as confirmed by the online NHS Health Research Authority decision-making tool (http://www.hra-decisiontools. org.uk/research/)). Each contributing centre ensured that they had appropriate institutional approval for the use of all data.

Provenance and peer review Not commissioned; externally peer reviewed.

Data sharing statement No additional data are available.

Open Access This is an Open Access article distributed in accordance with the Creative Commons Attribution Non Commercial (CC BY-NC 4.0) license, which permits others to distribute, remix, adapt, build upon this work non-commercially, and license their derivative works on different terms, provided the original work is properly cited and the use is non-commercial. See: http://creativecommons.org/ licenses/by-nc/4.0/

(C) Article author(s) (or their employer(s) unless otherwise stated in the text of the article) 2018. All rights reserved. No commercial use is permitted unless otherwise expressly granted.

\section{REFERENCES}

1. Joint Royal Colleges Ambulance Liaison Committee and Association of Ambulance Chief Executives. UK Ambulance Services Clinical Practice Guidelines. Bridgwater: Class Professional Publishing, 2016.

2. National Clinical Guideline Centre (UK). Major trauma: assessment and initial management. London: National Institute for Health and Care Excellence (UK), 2016. NICE Guideline, No. 39. https://www. ncbi.nlm.nih.gov/books/NBK344252

3. Holcomb JB, Swartz MD, DeSantis SM, et al. Multicenter observational prehospital resuscitation on helicopter study. J Trauma Acute Care Surg 2017;83:S83-91.

4. Smith IM, James RH, Dretzke J, et al. Prehospital Blood Product Resuscitation for Trauma: A Systematic Review. Shock 2016;46:3-16.

5. Lyon RM, de Sausmarez E, McWhirter E, et al. Pre-hospital transfusion of packed red blood cells in 147 patients from a UK helicopter emergency medical service. Scand J Trauma Resusc Emerg Med 2017;25:12.

6. Lockey DJ, Weaver AE, Davies GE. Practical translation of hemorrhage control techniques to the civilian trauma scene. Transfusion 2013;53(Suppl 1):17S-22.

7. Brown JB, Guyette FX, Neal MD, et al. Taking the Blood Bank to the Field: The Design and Rationale of the Prehospital Air Medical Plasma (PAMPer) Trial. Prehosp Emerg Care 2015;19:343-50.

8. Smith IM, Crombie N, Bishop JR, et al. RePHILL: protocol for a randomised controlled trial of pre-hospital blood product resuscitation for trauma. Transfus Med. 2017. In Press.

9. Jost D, Lanoe V. Pre-hospital Administration of Lyophilized Plasma for Post-traumatic Coagulopathy Treatment (PREHO-PLYO). Bethseda: National Institutes of Health, 2017. https://clinicaltrials. gov/ct2/show/NCT02736812

10. Raitt JE, Norris-Cervetto E, Hawksley O. A report of two years of prehospital blood transfusions by Thames Valley Air Ambulance. Trauma 2017:146040861770638.

11. Rehn M, Weaver A, Eshelby S, et al. London's Air Ambulance: 3 year experience with pre-hospital transfusion. Resuscitation 2015;96:156.

12. Hooper N, Baskerville M, Pynn HJ, et al. Pre-hospital Blood Developing a Service. Trauma 2017;19:234.

13. Holcomb JB, Swartz MD, DeSantis SM, et al. Multicenter observational prehospital resuscitation on helicopter study. J Trauma Acute Care Surg 2017;83:S83-S91.

14. Rossaint R, Bouillon B, Cerny V, et al. The European guideline on management of major bleeding and coagulopathy following trauma: fourth edition. Crit Care 2016;20:100.

15. Turner J, Nicholl J, Webber L, et al. A randomised controlled trial of prehospital intravenous fluid replacement therapy in serious trauma. Health Technol Assess 2000;4:1-57.

16. Bickell WH, Wall MJ, Pepe PE, et al. Immediate versus delayed fluid resuscitation for hypotensive patients with penetrating torso injuries. N Engl J Med 1994;331:1105-9.

17. Kaweski SM, Sise MJ, Virgilio RW. The effect of prehospital fluids on survival in trauma patients. J Trauma 1990;30:1215-9.

18. Cayten CG, Murphy JG, Stahl WM. Basic life support versus advanced life support for injured patients with an injury severity score of 10 or more. J Trauma 1993;35:460-7.

19. Hampton DA, Fabricant LJ, Differding J, et al. Prehospital intravenous fluid is associated with increased survival in trauma patients. J Trauma Acute Care Surg 2013;75:S9-15.

20. Haut ER, Kalish BT, Cotton BA, et al. Prehospital intravenous fluid administration is associated with higher mortality in trauma patients: a National Trauma Data Bank analysis. Ann Surg 2011;253:371-7.

21. Geeraedts LM, Pothof LA, Caldwell E, et al. Prehospital fluid resuscitation in hypotensive trauma patients: do we need a tailored approach? Injury 2015;46:4-9.

22. Sasser SVM, Kellermann A, Lormand JD. Prehospital trauma care systems. Geneva: World Health Organization, 2005. http://www.who. int/violence_injury_prevention/publications/services/39162_oms_ new.pdf

23. Institute of Medicine. Emergency medical services: at the crossroads. Washington, DC: The National Academies Press, 2007.

24. Pocock H, Deakin CD, Quinn T, et al. Human factors in prehospital research: lessons from the PARAMEDIC trial. Emerg Med $\mathrm{J}$ 2016;33:562-8.

25. Tiboni S, Bhangu A, Hall NJ; Paediatric Surgery Trainees Research Network and the National Surgical Research Collaborative. Outcome of appendicectomy in children performed in paediatric surgery units compared with general surgery units. Br J Surg 2014;101:707-14.

26. CholeS Study Group, West Midlands Research Collaborative. Population-based cohort study of outcomes following cholecystectomy for benign gallbladder diseases. Br J Surg 2016;103:1704-15

27. Bhangu A, Kolias AG, Pinkney T, et al. Surgical research collaboratives in the UK. Lancet 2013;382:1091-2.

28. Chapman SJ, Glasbey JC, Khatri C, et al. Promoting research and audit at medical school: evaluating the educational impact of participation in a student-led national collaborative study. BMC Med Educ 2015;15:47.

29. David JS, Voiglio EJ, Cesareo E, et al. Prehospital parameters can help to predict coagulopathy and massive transfusion in trauma patients. Vox Sang 2017;112:557-66. 